\title{
EDITORIAL
}

\section{The ethological approach to aggression ${ }^{1}$}

There are several ways in which ethology, the biological study of behaviour, can contribute to our understanding of aggression. First of all, by studying animals we can get some idea of what aggression is and how it relates to other, similar patterns of behaviour. We can also begin to grasp the reasons why natural selection has led to the widespread appearance of apparently destructive behaviour. To come to grips with this question requires the study of animals in their natural environment, for this is the environment to which they are adapted and only in it can the survival value of their behaviour be appreciated. By contrast, a final contribution of ethology, that of understanding the causal mechanisms underlying aggression, usually comes from work in the laboratory, for such research requires carefully controlled experiments. Ethology has shed light on all these topics, perhaps particularly in the 15 years since Konrad Lorenz, one of the founding fathers of the discipline, discussed the subject in his book On Aggression. Lorenz's views were widely publicized and had great popular appeal: the fact that few ethologists agreed with what he said may explain why so many have since devoted time to studying aggression. The result, as I shall argue here, is that ethologists now have a much better insight into what aggression is, how it is caused and what functions it serves, and it is an insight sharply at odds with the ideas put forward by Lorenz.

The first problem is that of definition. Ethologists usually group behaviour patterns according to their form, those that look most similar being categorized together. This works very well for behaviour such as feeding or grooming, where the motor patterns are not too diverse, but it would clearly be hopeless in the case of aggression because it can be expressed in so many different actions. As most people who study aggression are primarily interested in its causes, what they would like to achieve is a definition in which the behaviour patterns included have a common causal basis, sharing internal and external stimuli and a neural substrate. But evidence on this is hard to obtain and behaviour patterns are usually defined as being aggressive before it is known whether they share a motivational basis. Patterns are, in fact, most often classified as aggressive according to their consequences rather than their causes. For example, Hinde (1974) defines aggression as 'behaviour directed toward causing physical injury to another individual', a definition entirely in terms of effects rather than causes, yet one which expresses reasonably well what an ethologist means by aggression.

The important question is the extent to which a classification such as this is likely to coincide with a causal one. Hinde restricts his definition somewhat to increase the chance that it does. He excludes intergroup strife or warfare as these are likely to be quite differently caused from aggression between individuals. He also rules out predatory behaviour on similar grounds. It is certainly true that some of the actions involved in prey capture are very similar to those shown when two animals of the same species fight, as might be expected because there are a limited number of ways in which one animal can inflict damage upon another. It is possible that the mechanisms underlying predation and aggression also have much in common, but it is essential that this is not assumed to be so simply because they involve similar actions. They are likely to differ in their neural and physiological bases, as they do in the stimuli that elicit them, for the simple reason that they subserve quite different functions. This is one reason why ethologists are very doubtful of the value of studying mouse-killing by rats: although this looks like aggression, it is quite likely to have little in common with it as far as causes are concerned. If behaviour patterns which are differently caused are lumped together it just confuses the issue. For this reason too it seems preferable to study offensive aggression as a separate phenomenon from the defensive aggression shown by an animal cornered by a conspecific or a predator: the latter has more in common with fleeing than with attack (Archer, 1976).

1 Address for correspondence: Dr P. J. B. Slater, Biology Building, University of Sussex, Falmer, Sussex BN1 9QG.

\section{3-2917/80/2828-5530 \$01.00 (c) 1980 Cambridge University Press}


Aggression has, therefore, to be very precisely defined to avoid including in the category various aspects of behaviour which are differently caused. Even where this is done, however, ethological studies have shown that the causes of aggression can vary considerably between species. Lorenz thought that animals had an innate aggressive drive, which rose with time since they last behaved aggressively and was expended when aggressive behaviour was being shown. This view was based partly on the analogy between aggression and behaviour patterns such as feeding and drinking which, being aimed at correcting a physiological deficit, certainly rise in likelihood with deprivation. Isolated animals also become more prone to fight, but this is as likely to be because they habituate to other animals when in company and then dishabituate when on their own as because of the accumulation of some supposed drive. Natural selection has equipped animals with mechanisms which are marvellously well adapted to the requirements of their particular way of life: there is no reason why different patterns of behaviour, like feeding and aggression, should rely on similar mechanisms, nor that a pattern such as aggression should have a similar basis in different species. The latter point is well illustrated by the way in which the hormones affecting aggression vary between species according to the exact circumstances in which they need to show this behaviour (Slater, 1979).

So much for the causes of aggression; what then of its functions? The word function is used by biologists in a rather special sense to indicate the selective advantage or survival value of a particular characteristic. For a long time many biologists believed that natural selection acted for the good of the species or group to which an animal belonged. This made it hard to understand why animals within a species or group should behave in a destructive manner towards one another, although it was sometimes argued that spacing out or population control made it beneficial. In the past few years, however, there has been a revolution in thinking about how natural selection works and it has become clear that selection at the level of the species or group is unlikely to be of much importance compared with that at the level of the individual. From this comes the general rule, which seems well matched by observations on behaviour, that individuals should follow their own self-interest or, to be more precise, that of their genes (Dawkins, 1976).

With such a rule, the problem is not to explain the existence of aggression but why there is so little of it. There are several possible reasons for this. One is that animals in groups tend to be related to each other so that aggression between them does not help the survival of their shared genes and is thus discouraged by selection. Secondly, in long lived groups, cooperative relationships may arise between individuals to their mutual benefit, regardless of whether they are related or not. This is known as reciprocal altruism, and is obviously particularly well developed in humans. But there is a third reason why aggression is not more widespread, and this is perhaps the most important. An animal should only indulge in a fight when the likely costs are less than the likely benefits, both costs and benefits being measured in terms of Darwinian fitness (loss or gain of reproduction). Where death is a possible cost, the reward for winning must be very high if it is to be worth fighting. This is one reason why many animal contests have become ritualized so that little blood is spilt and the outcome is determined more by convention than by force (Maynard Smith, 1978).

Do these findings on animal aggression have any relevance for human behaviour? Lorenz considered the aggressive drive that he proposed to be innate, with the implication that it was genetically determined and could not be modified, so that harmless ways of expending it had to be discovered. But genetic determination does not work like that. Natural selection has led to the survival of genes which give appropriate behaviour in the natural environment of the animal. As many experiments have shown, no matter how constant the behaviour normally is, if the animal develops in an unnatural environment the outcome may be quite different. There is no reason to think that the development of aggression is any exception. In the case of man this has two main implications. First, because most humans now live in a very different environment from that to which natural selection adapted them, their behaviour may develop to be inappropriate or even maladaptive in some respects. Secondly, on a more optimistic note, because genes merely give potentialities, which can be realized or not depending on the environment, there is no reason to regard human aggression as being unmodifiable. From their other activities, all the indications are that individual humans often fail to 
behave in the selfish way that their genes would prefer: contraception, abortion and adoption are hardly practices which natural selection would encourage. It would be a mistake to think that aggression is necessarily different so that neither education nor environmental changes can affect it.

P. J. B. SLATER

\section{REFERENCES}

Archer, J. (1976). The organisation of aggression and fear in vertebrates. In Perspectives in Ethology Vol. 2 (ed. P. P. G. Bateson and P. H. Klopfer), pp. 231-296. Plenum Press : New York.

Dawkins, R. (1976). The Selfish Gene. Oxford University Press: Oxford.
Hinde, R. A. (1974). Biological Bases of Human Social Behaviour. McGraw-Hill: New York.

Lorenz, K. (1966). On Aggression. Methuen: London.

Maynard Smith, J. (1978). The evolution of behavior. Scientific American 239 (3), 136-145.

Slater, P. J. B. (1979). The ethology of aggression. In The Psychopharmacology of Aggression (ed. M. Sandler), pp. 519. Raven Press: New York. 